\title{
Theranostics: Leveraging Molecular Imaging and Therapy to Impact Patient Management and Secure the Future of Nuclear Medicine
}

\author{
Lilja B. Solnes ${ }^{1}$, Rudolf A. Werner ${ }^{1,2}$, Krystyna M. Jones ${ }^{1}$, Mohammad S. Sadaghiani ${ }^{1}$, Christopher R. Bailey ${ }^{1}$, \\ Constantin Lapa ${ }^{3}$, Martin G. Pomper ${ }^{1}$, and Steven P. Rowe ${ }^{1}$ \\ ${ }^{I}$ Russell H. Morgan Department of Radiology and Radiological Science, Johns Hopkins University School of Medicine, Baltimore, \\ Maryland; ${ }^{2}$ Department of Nuclear Medicine, Hannover Medical School, Hannover, Germany; and ${ }^{3}$ Department of Nuclear \\ Medicine, University Hospital Augsburg, Augsburg, Germany
}

Nuclear medicine is experiencing a renaissance, with U.S. Food and Drug Administration approval recently being obtained for theranostic agents and a wide variety of such agents soon to impact patient care significantly in the era of precision medicine. The NETTER-1 trial demonstrated the therapeutic effect of a theranostic agent in markedly improving progression-free survival in patients with metastatic gastroenteropancreatic neuroendocrine tumors. Predominantly retrospective studies have demonstrated a significant response to ${ }^{177}$ Lu-labeled agents targeting prostate-specific membrane antigen (PSMA) in patients with prostate cancer. At least 2 prospective clinical trials involving ${ }^{177} \mathrm{Lu}$-PSMA agents are under way that will likely pave the way for Food and Drug Administration approval in the United States. A significant upside to theranostics is that patients tend to tolerate these agents better than chemotherapy. Theranostic compounds are likely to impact many cancers in the near future, not only through improvements in quality of life but also in terms of survival. This article provides an overview of already approved agents as well as those on the horizon. It is important that as these agents are clinically onboarded, nuclear medicine physicians have the expertise to deploy theranostics safely and efficiently, ensuring that these agents attain and maintain their position as leading lines of therapy in managing patients with cancer as well as becoming an important aspect of nuclear medicine practice in the future.

Key Words: SSTR; PSMA; ${ }^{177} \mathrm{Lu}$; ${ }^{131} \mathrm{I}$; endoradiotherapy

J Nucl Med 2020; 61:311-318

DOI: 10.2967/jnumed.118.220665

$\mathbf{T}$ heranostics is one of the oldest subfields within nuclear medicine, tracing its roots to the original application of ${ }^{131} \mathrm{I}$ for the treatment of thyroid disease $(1,2)$. ${ }^{131}$ I-based therapy for thyroid cancer is the quintessential example of the theranostic principle. ${ }^{131}$ I was discovered by Seaborg and Livingood in 1938. After his

Received Jul. 22, 2019; revision accepted Jan. 3, 2020.

For correspondence or reprints contact: Lilja B. Solnes, Division of Nuclear Medicine and Molecular Imaging, Russell H. Morgan Department of Radiology and Radiological Science, Johns Hopkins University School of Medicine, Baltimore, MD 21287

E-mail: Isolnes1@jhmi.edu

Published online Jan. 10, 2020.

COPYRIGHT (c) 2020 by the Society of Nuclear Medicine and Molecular Imaging. observations on animal studies, Saul Hertz used ${ }^{131} \mathrm{I}$ as the first theranostic agent in 1941 for treating a patient with hyperthyroidism. For decades, ${ }^{131}$ I remained the sole commonly used example of a radiotracer capable of both diagnosis and therapy. With eventual easier accessibility to the diagnostic radionuclide ${ }^{123} \mathrm{I},{ }^{123} \mathrm{I} /{ }^{131} \mathrm{I}$ became the first theranostic pair to find widespread clinical adoption in nuclear medicine. Ultimately, radioiodine therapy provided an important proof of principle, although it was many years before new therapeutic radionuclides and theranostic agents became available (Table 1).

Confirming the presence of a target with molecular imaging and then using that target to deliver radiation in a precise manner is an intuitive approach with applications far beyond thyroid disease. Radiolabeled antibodies have been used for targeted endoradiotherapy in lymphoma $(3,4)$ and solid tumors $(5)$. However, it has been the introduction of multiple small-molecule theranostic pairs in recent years that has revitalized the nuclear medicine community. With the U.S. Food and Drug Administration (FDA) approval of ${ }^{177}$ Lu-DOTATATE and high-specific-activity ${ }^{131}$ I-metaiodobenzylguanidine (MIBG) (Azedra; Progenics Pharmaceuticals, Inc.), a renaissance in theranostics is now worldwide and gaining momentum.

In the era of precision medicine, theranostics are likely to become increasingly important in patient care. The use of advanced diagnostics to select patients for targeted therapy is the very essence of precision medicine. Nuclear medicine physicians are uniquely equipped, and have a responsibility, to shepherd these valuable new agents to clinical care, working collaboratively with referring providers to determine at what point in the patient's treatment pathway such agents should be deployed. Here, we provide an overview of the current state of therapy in nuclear medicine, and we highlight future directions.

\section{U.S. FDA-APPROVED THERANOSTIC AGENTS}

\section{High-Specific-Activity ${ }^{131}$ I-MIBG}

${ }^{131}$ I-MIBG has been used off-label in association with chemotherapy to treat metastatic neuroblastoma and pheochromocytoma for years $(6,7)$. MIBG is a substrate for the norepinephrine uptake transporter and localizes to neuroendocrine cells. That allows for diagnosis and follow-up assessment (using ${ }^{123} \mathrm{I}-\mathrm{MIBG}$ or ${ }^{131} \mathrm{I}-\mathrm{MIBG}$ ) or treatment (using ${ }^{131} \mathrm{I}-\mathrm{MIBG}$ ) of tumors.

Indications for therapy are nonresectable, metastatic pheochromocytoma or paraganglioma, neuroblastoma, and recurrent metastatic 
TABLE 1

Physical Characteristics of Common Radionuclides Used in Radiotherapy (89)

\begin{tabular}{lclc}
\hline Radionuclide & Half-life $(h)$ & \multicolumn{1}{c}{ Maximum energy } & Maximum particle range in soft tissue $(\mathrm{mm})$ \\
\hline${ }^{177} \mathrm{~L}$ & 162 & $\beta(498 \mathrm{keV}), \mathrm{Y}(208 \mathrm{keV})$ & 2 \\
${ }^{90} \mathrm{Y}$ & 64 & $\beta(2,250 \mathrm{keV})$ & 11 \\
${ }^{131} \mathrm{I}$ & 193 & $\beta(610 \mathrm{keV}), \mathrm{y}(362 \mathrm{keV})$ & 2.9 \\
${ }^{225} \mathrm{Ac}$ & 240 & $\mathrm{a}(6 \mathrm{MeV})$ & No clear range because of successive a-emissions \\
\hline
\end{tabular}

medullary thyroid cancer (8). Possible side effects include nausea and vomiting, as well as longer-term effects such as hypothyroidism and myelosuppression, which must be monitored closely during treatment. Although rare, hematologic malignancies may occur after treatment $(9,10)$.

Recently, the FDA approved a high-specific-activity formulation of ${ }^{131}$ I-MIBG. The difference between the high-specific-activity formulation and the conventional ${ }^{131} \mathrm{I}-\mathrm{MIBG}$ regimen is that the level of nonradiolabeled MIBG in the therapeutic dose is significantly less, resulting in higher specific activity. High levels of nonradiolabeled MIBG may increase the risk of a hypertensive crisis during or immediately after the infusion $(11,12)$. Therefore, high-specific-activity radiopharmaceutical administration is likely to reduce peritreatment complications and allow for a greater treatment effect with a lower infusion dose. Pryma et al. recently published phase II results for patients with metastatic pheochromocytoma or paraganglioma and showed that the treatment was safe and effective (Fig. 1), resulting in sustained control of catecholamine-induced hypertension in $25 \%$ of patients and a sustained antitumor effect in $22 \%$ of patients (13). The study reported no hypertensive complications during the infusion period.

${ }^{131}$ I-MIBG therapy may also be considered for other neuroendocrine tumors (NETs) demonstrating sufficient uptake of radiotracer on diagnostic imaging. A retrospective analysis of 25 patients with NETs treated with conventional ${ }^{131}$ I-MIBG therapy after a positive ${ }^{123}$ I-MIBG scan demonstrated symptomatic control in $80 \%$ of patients, hormonal response in 55\%, and tumor response in $48 \%$ (14). Limited assessment is available for the efficacy of ${ }^{131} \mathrm{I}$-MIBG therapy in patients with medullary thyroid cancer. Castellani et al. reported on their experience in this patient population. Thirteen patients with medullary thyroid cancer were treated with conventional ${ }^{131}$ I-MIBG therapy, with 4 patients demonstrating partial disease response and 4 patients having stable disease after therapy (15). A phase II trial for neuroblastoma examining the utility of conventional ${ }^{131}$ I-MIBG therapy showed an objective response rate of $36 \%$, which is promising in light of the fact that these patients have heavily pretreated disease; $34 \%$ had stable disease for a median of $6.2 \mathrm{mo}$, with a large proportion of patients reporting pain

\section{NOTEWORTHY}

- Theranostic agents are likely to play a prominent role as patient care strategies become more precision-oriented.

- Recent FDA-approved theranostics have a significant impact on patient outcomes.

- Nuclear medicine physicians are positioned to lead in the administration of FDA-approved theranostics and introduction of new agents into the clinical arena. relief (16). A phase IIa trial for high-specific-activity ${ }^{131} \mathrm{I}-\mathrm{MIBG}$ yielded promising results in terms of safety and efficacy in the treatment of refractory neuroblastoma (17). Further studies are required to assess whether there is any benefit over the conventional formulation of ${ }^{131}$ I-MIBG and whether there is an overall survival benefit $(14-16,18)$.

\section{${ }^{177}$ Lu-DOTATATE}

Although ${ }^{177} \mathrm{Lu}$-labeled somatostatin analog therapy has been available in Europe for decades, ${ }^{177} \mathrm{Lu}$-DOTATATE was not approved in the United States by the FDA until 2018. It is a tool for the treatment of progressive, metastatic NETs, which most commonly arise from respiratory epithelium, pancreas, or gastroenteric tissue (19). The FDA did not approve ${ }^{177} \mathrm{Lu}$-DOTATATE for use in patients with primary pulmonary NETs. NETs may histologically be well differentiated or poorly differentiated; ${ }^{177}$ Lu-DOTATATE binds to somatostatin receptor II. To ensure that the treatment is indicated, patients generally undergo ${ }^{68} \mathrm{Ga}$-DOTATATE PET/CT to document radiotracer-avid disease.

There are multiple therapeutic options for patients presenting with metastatic NETs, including somatostatin analogs, chemotherapy, and radioembolization of liver lesions. However, the NETTER-1 trial data suggest that ${ }^{177} \mathrm{Lu}$-DOTATATE may offer patients with progressive, metastatic disease the best option for improved progression-free survival (20). The 2 arms of the NETTER-1 trial consisted of patients who received either a high-dose, long-acting octreotide formulation $(60 \mathrm{mg})$ or a ${ }^{177} \mathrm{Lu}-$ DOTATATE regimen with low-dose, long-acting octreotide $(30 \mathrm{mg})$. Median progression-free survival was not reached in the ${ }^{177} \mathrm{Lu}$-DOTATATE group and was $8.4 \mathrm{mo}$ in the high-dose octreotide group. Although the follow-up period was short, interim analysis suggests that the risk of death was $60 \%$ lower in the group receiving ${ }^{177} \mathrm{Lu}$-DOTATATE

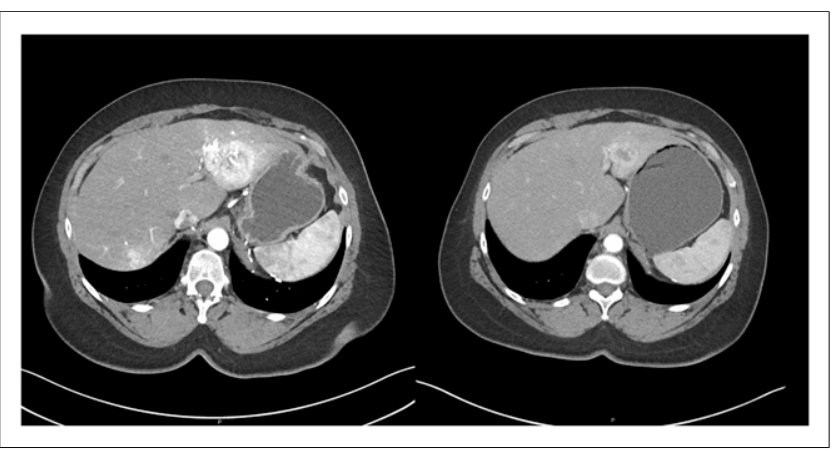

FIGURE 1. Axial contrast-enhanced CT scans through liver in patient with metastatic paraganglioma demonstrating significant response to high-specific-activity ${ }^{131}$ I MIBG therapy. Images before and 12 mo after initiation of therapy demonstrate marked decrease in size of lesions in left lobe and resolution of lesion in right lobe. 
(21). Although the NETTER-1 trial included only patients with midgut NETs, there is significant retrospective data supporting the use of PRRT in NETs of other origins, including bronchial and hindgut (22).

When to administer the drug in a patient's disease course is not well delineated at present (23). First-line therapy options are dependent on tumor origin, grade, and patient condition (23-26). In our experience, PRRT is most often considered as a second-line agent and beyond. A minority of patients who respond will demonstrate complete regression of disease after therapy, but most patients will have stable to minimally regressed disease on followup imaging (Fig. 2). There is no set standard for when to reimage patients after therapy. The literature has suggested that in patients with low-grade disease, less frequent surveillance imaging and laboratory assessment are required, whereas those with high-grade disease may benefit from more frequent assessment $(21,27)$. Imaging during therapy is generally not indicated, because true response may be masked by pseudoprogression (28). Imaging during therapy can be considered in patients with aggressive histologic disease or suspicion of progression based on clinical evaluation (29). There are also no prospective data examining the benefit of retreatment of patients with ${ }^{177} \mathrm{Lu}$-DOTATATE should they progress. Retrospective data suggest that some patients may benefit from retreatment, having improved progression-free survival (30).

${ }^{177} \mathrm{Lu}$-DOTATATE therapy is likely to play a role in the treatment of other malignancies. Pheochromocytomas and paragangliomas may demonstrate significant uptake on ${ }^{68} \mathrm{Ga}$-DOTATATE PET imaging due to somatostatin receptor expression. PRRT has been shown in a retrospective study to be efficacious for the treatment of unresectable pheochromocytoma and paraganglioma. Although follow-up time was limited, Kong et al. demonstrated regression or stabilization of disease based on morphologic imaging, as well as reduction in hypertension medications in more than half of the

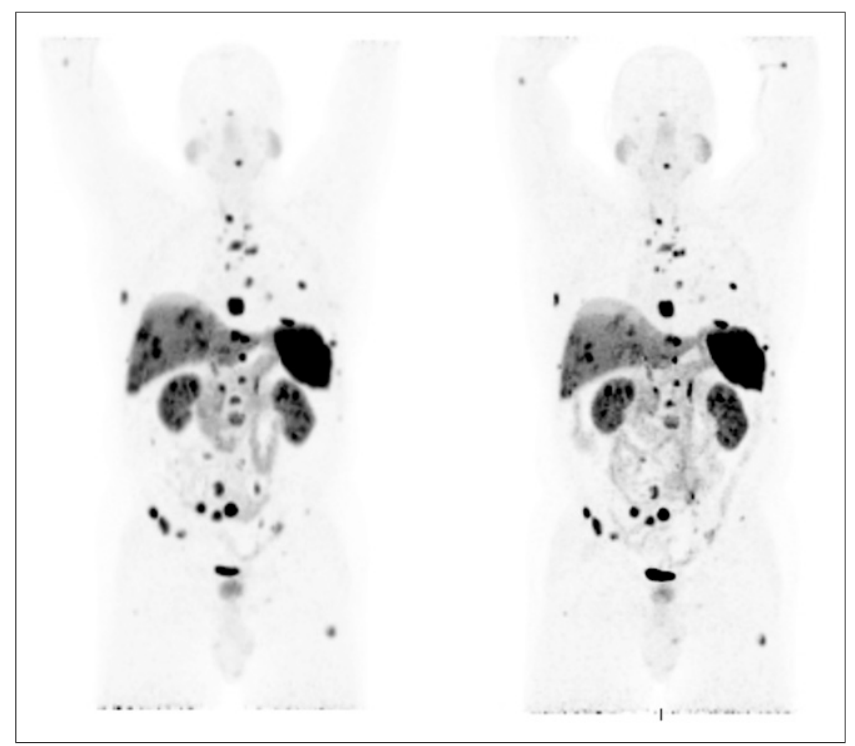

FIGURE 2. A 70-y-old man with metastatic bronchial carcinoid who underwent ${ }^{177} \mathrm{Lu}$-DOTATATE therapy. (Left) Pretreatment scan demonstrates marked metastatic disease in orbit, lungs, and bones that had been progressing on chemotherapy. (Right) Subsequent ${ }^{68} \mathrm{Ga}$-DOTATATE scan demonstrates mild decrease in tumor volume 6 mo after treatment completion (arrested disease). patients (31). Meningiomas are also known to express somatostatin receptors. Although meningiomas are usually benign and slow-growing, a small percentage may be atypical or malignant. Tumors with more aggressive histologic features have a high recurrence rate after resection (32). A trial of 29 patients with recurrent meningioma that had exhausted all therapy options explored the efficacy of ${ }^{90}$ Y-labeled somatostatin analog therapy and found that it may slow progression of disease (33). A combination of externalbeam radiotherapy and PRRT has shown some promise in these patients. A study of 10 patients with nonresectable meningioma treated with PRRT and external-beam radiotherapy reported no morphologic tumor progression and mild side effects (34). Further prospective studies are needed. Additional disease states that demonstrate high somatostatin receptor expression may benefit from PRRT, such as medullary thyroid cancer, solid cancers with neuroendocrine differentiation, and Merkel cell cancer (potentially in combination with immunotherapy) (31,33-39).

\section{${ }^{223}$ Ra-Dichloride Therapy}

${ }^{223}$ Ra-dichloride (Xofigo; Bayer HeathCare Pharmaceuticals Inc.) (technically not a theranostic agent, but a therapy agent within the arsenal of treatment options in nuclear medicine) is a calcium mimic and $\alpha$-particle emitter that targets areas of increased bone turnover (40-42). Because elevated bone turnover commonly occurs in osseous metastases, ${ }^{223} \mathrm{Ra}$ has been developed as a targeted therapy for symptomatic bone metastases in prostate cancer, a common cause of morbidity and mortality in patients with metastatic disease (43). After multiple phase II studies (44-46), a phase III randomized, double-blind, placebo-controlled study of 921 patients with metastatic castration-resistant prostate cancer (mCRPC) with isolated osseous metastases provided the primary evidence on which is based clinical treatment of patients with ${ }^{223} \mathrm{Ra}(47)$. The primary endpoint was overall survival, and there were multiple secondary endpoints, including the time required for serum prostatespecific antigen (PSA) to show an increase (47).

${ }^{223} \mathrm{Ra}$ therapy was found to be both safe and effective in improving overall survival, with a $30 \%$ reduction in mortality in the treatment group, compared with placebo (median overall survival of 14.0 mo in the ${ }^{223} \mathrm{Ra}$ group and $11.2 \mathrm{mo}$ in the placebo group) (47). That finding was consistent across all patient subgroups. All secondary endpoints also favored ${ }^{223} \mathrm{Ra}$ over placebo, including a significantly longer time to a symptomatic skeletal event (defined as a fracture, the need for targeted radiation therapy, an orthopedic intervention for skeletal metastasis, or spinal cord compression) (47). The safety profile of ${ }^{223} \mathrm{Ra}$ was also demonstrated, with the rates of all adverse events being higher in the placebo group. For instance, in mild symptomatic mCRPC patients who were chemotherapy-naïve and whose tumor burden was predominantly in the skeleton, ${ }^{223} \mathrm{Ra}$ plus abiraterone acetate plus prednisone/ prednisolone was compared with placebo plus abiraterone acetate plus prednisone/prednisolone. In the ${ }^{223} \mathrm{Ra}$ arm, an increased excessfracture and death rate was noted; this phase III trial was therefore unmasked early $(48,49)$. Nonetheless, the safety profile of ${ }^{223} \mathrm{Ra}$ is favorable, and it is a viable therapeutic option for men who meet the FDA-approved indication (i.e., men with mCRPC, symptomatic bone metastases, and no known visceral metastases) (50). With regard to castration-sensitive prostate cancer, there is also emerging evidence that men with bone metastases can benefit from therapy with ${ }^{223} \mathrm{Ra}(51,52)$; this possibility continues to be actively investigated (e.g., ClinicalTrials.gov identifier NCT03304418). However, the risk-benefit profile of ${ }^{223} \mathrm{Ra}$ in certain prostate cancer clinical 
scenarios may propel the adoption of ${ }^{177} \mathrm{Lu}$-prostate-specific membrane antigen (PSMA) therapy (e.g., a recently published single-center, prospective phase II trial [LuPSMA trial] reported high response rates, low toxic effects, and reduction of pain in men with progressive mCRPC after treatment with PSMA-targeted therapy (53)).

Even if ${ }^{177} \mathrm{Lu}-\mathrm{PSMA}$ comes to play a prominent role in prostate cancer, ${ }^{223}$ Ra may find clinical applicability in other malignancies. ${ }^{223} \mathrm{Ra}$ appears to be safe, well tolerated, and biologically active in patients with breast cancer and predominantly bone metastatic disease (54). The combination of ${ }^{223} \mathrm{Ra}$ with therapy targeted against vascular endothelial growth factor decreases bone turnover markers and led to objective response rates in a subset of patients with bone-metastatic renal cell carcinoma (55). The utility of ${ }^{223} \mathrm{Ra}$ therapy in nonprostate cancers, either alone or in combination with other therapies, remains to be elucidated but is under active investigation (e.g., ClinicalTrials.gov identifier NCT02283749).

\section{ON THE FDA HORIZON: ${ }^{177}$ LU-PSMA RADIOLIGAND THERAPY}

PSMA is expressed in prostate cancer and shows increased expression in mCRPC (56). The first small-molecule radioligand targeting PSMA for therapeutic purposes was ${ }^{131} \mathrm{I}-\mathrm{MIP}-1095$, although ${ }^{177} \mathrm{Lu}$-based agents (including ${ }^{177} \mathrm{Lu}-\mathrm{PSMA}-617$ and ${ }^{177} \mathrm{Lu}-\mathrm{PSMA}-$ I\&T), collectively referred to here as ${ }^{177} \mathrm{Lu}$-PSMA, have seen more clinical use (57). ${ }^{177} \mathrm{Lu}$-PSMA ligands are $\beta$-particle emitters that target PSMA-expressing tumors and have been used primarily in mCRPC (58).

A 2016 study by Kratochwil et al. demonstrated the safety and efficacy of ${ }^{177} \mathrm{Lu}-\mathrm{PSMA}$ therapy in a small cohort of 30 patients with mCRPC, each of whom received 1-3 cycles (59). Thirteen of 30 patients experienced a PSA decrease of more than $50 \%$ after therapy, with no significant decline in renal or liver function during the study period. Myelotoxicity, including leukopenia, anemia, and thrombocytopenia, occurred infrequently and most often in patients with baseline diffuse bone marrow metastases.

A larger 2016 study by Baum et al. included 56 patients with mCRPC, each of whom received $2-4$ cycles of ${ }^{177} \mathrm{Lu}-\mathrm{PSMA}$ radioligand therapy (60). A PSA reduction was seen in $80 \%$ of patients, whereas a PSA reduction of more than $50 \%$ was reported in $59 \%$. Additionally, $33 \%$ of patients reported decreased pain after treatment. Adverse events were infrequent and mild, with no significant nephrotoxicity or hematotoxicity.

A 2017 retrospective multicenter study conducted by Rahbar et al. involved 145 patients with mCRPC from 12 centers, all of whom had received at least 1 cycle of ${ }^{177} \mathrm{Lu}-\mathrm{PSMA}$ therapy followed by further therapies 8-12 wk apart (61). The primary study endpoint was biochemical response, defined as a PSA decline of more than $50 \%$. In total, $45 \%$ of patients had a biochemical response to therapy. Grade 3 or 4 hematologic events were uncommon and were seen in 18 patients (12\%). Mild to moderate xerostomia occurred in 11 patients $(8 \%)$, and nausea was reported in $6 \%$ of patients.

On the basis of studies demonstrating the safety and efficacy of ${ }^{177}$ Lu-PSMA therapy, the German Society of Nuclear Medicine issued consensus recommendations in 2016 detailing the indications for use of these agents, which currently includes patients with mCRPC with detectable PSMA uptake on ${ }^{68} \mathrm{Ga}$-PSMA PET/ $\mathrm{CT}$ and evidence of biochemical or radiologic disease progression on standard therapy. Nonetheless, ${ }^{177}$ Lu-PSMA therapy remains investigational (62). To determine the overall survival benefit of this therapy in patients with metastatic prostate cancer, a standardized, prospective trial of ${ }^{177} \mathrm{Lu}$-PSMA radioligand therapy is ongoing across multiple centers in the United States and Europe (ClinicalTrials.gov identifier NCT03511664). Secondary objectives of this trial include radiographic progression-free survival, RECIST response, and time to first symptomatic skeletal event. If a survival benefit can be found, ${ }^{177} \mathrm{Lu}$-PSMA may become an integral therapy in the treatment of patients with advanced prostate cancer.

Further prospective studies are also needed to elucidate the appropriate timing of PSMA-targeted endoradiotherapy in prostate cancer and to ascertain any role these agents may have in treating nonprostate malignancies with epithelial or endothelial PSMA expression (63). Additionally, more potent PSMA-targeted endoradiotherapeutics labeled with $\alpha$-emitting radionuclides such as ${ }^{225} \mathrm{Ac}$ are being investigated and can elicit profound responses in patients with advanced prostate cancer (64). However, the toxicity profile, particularly quality-of-life-altering xerostomia, of the PSMA-targeted, $\alpha$-emitting agents may limit the adoption of these compounds into the clinic (65).

\section{EMERGING THERANOSTIC AGENTS}

\section{Lu-Pentixather}

Mesenchymal or marrow-derived stromal cells constantly secrete the chemokine stromal cell-derived factor-1 (SDF-1/CXCL12), which in turn attracts cancer cells by interacting with its cognate receptor, CXCR4 (66). CXCR4, a cell-surface protein, plays a pivotal role in tumorigenesis, chemotaxis, and migration of metastatic tumor cells (67). CXCR4 has been observed in $75 \%$ of tumor entities, including pancreatic, breast, lung, prostate, and colorectal cancer $(68,69)$. Recent efforts have focused on the SDF-1/CXCR4 axis, such as the FDA-approved small-molecule CXCR4 antagonist plerixafor (Mozobil; Sanofi Genzyme) for stem cell mobilization $(68,70,71)$. Similar to plerixafor, the CXCR4 antagonist balixafortide demonstrated favorable results in combination with eribulin chemotherapy in patients with heavily pretreated, relapsed metastatic breast cancer (72).

Transferring the concept of the SDF-1/CXCR4 interaction to molecular imaging, CXCL12 conjugates have been labeled with radioisotopes, including the cyclic pentapeptide ${ }^{68} \mathrm{Ga}$-pentixafor (73). That imaging agent is the most extensively investigated CXCR4 radioligand to date $(73,74)$. Its theranostic twin, pentixather, radiolabeled with either ${ }^{177} \mathrm{Lu}$ or ${ }^{90} \mathrm{Y}$, has also been studied (Table 2) (75-77). Because of physiologic expression of CXCR4 in the bone marrow, and substantial retention of radioactivity in renal parenchyma, side effects include myelosuppression and deterioration in renal function. Consequently, peritherapeutic dosimetry is highly recommended (Fig. 3) (73). To achieve maximum tumor bone marrow ablation, endoradiotherapy with ${ }^{177} \mathrm{Lu}$ pentixather has been performed as an add-on to a conventional chemotherapy and conditioning regimen before autologous or allogeneic stem cell transplantation (73). For instance, Lapa et al. reported absorbed tumor doses of 30-70 Gy in intra- or extramedullary lesions in multiple myeloma, along with complete remission in 1 of 8 subjects and partial remission in 5 of 8 (76). To further corroborate those promising findings, the COLPRIT trial (EudraCT identifier 2015-001817-28) will investigate this theranostic approach in multiple myeloma and lymphoma prospectively (73). Future assessments may also focus on solid tumors, such as neuroendocrine neoplasias, small cell lung cancer, or adrenal cortical carcinoma (78-80), although this theranostic approach may need to 
TABLE 2

Overview of Emerging Theranostic Twins

\begin{tabular}{|c|c|c|c|c|}
\hline Theranostic twin & $\begin{array}{l}\text { Subcellular } \\
\text { mechanism }\end{array}$ & $\begin{array}{l}\text { Treated tumor } \\
\text { entities }\end{array}$ & Organs at risk & Key characteristics \\
\hline \multirow[t]{3}{*}{$\begin{array}{l}{ }^{68} \text { Ga-pentixafor/ } \\
177 \text { Lu-pentixather }\end{array}$} & $\begin{array}{l}\text { SDF1/CXCR4 } \\
\text { axis }\end{array}$ & $\begin{array}{l}\text { Multiple } \\
\text { myeloma }\end{array}$ & $\begin{array}{l}\text { Bone marrow, } \\
\text { kidney }\end{array}$ & $\begin{array}{l}\text { Agent has been applied for treatment of } \\
\text { multiple myeloma }(76,77) \text {, with complete/ } \\
\text { partial remission in most subjects }(76)\end{array}$ \\
\hline & & & & $\begin{array}{l}\text { Agent is add-on to conventional } \\
\text { chemotherapy and conditioning regimen } \\
\text { before autologous or allogeneic stem cell } \\
\text { transplantation (73) }\end{array}$ \\
\hline & & & & $\begin{array}{l}\text { COLPRIT trial investigates CXCR4-directed } \\
\text { endoradiotherapy in multiple myeloma and } \\
\text { lymphoma at early disease stage (73) }\end{array}$ \\
\hline \multirow[t]{3}{*}{${ }^{123} \mathrm{I}-/^{131} \mathrm{I}-\mathrm{metomidate}$} & $\begin{array}{l}11 \beta \text {-hydroxylase } \\
\text { aldosterone } \\
\text { synthase }\end{array}$ & $\begin{array}{l}\text { Adrenocortical } \\
\text { cancer }\end{array}$ & $\begin{array}{l}\text { Bone marrow, } \\
\text { adrenal gland }\end{array}$ & $\begin{array}{l}\text { Partial response was seen in } 1 / 11 \text { patients and } \\
\text { stable disease in } 5 / 11 \text { (83) }\end{array}$ \\
\hline & & & & $\begin{array}{l}\text { The novel theranostic pair }{ }^{123}|-|^{131} \mid- \\
\text { azetidinylamide may increase efficacy (84) }\end{array}$ \\
\hline & & & & $\begin{array}{l}\text { The currently recruiting FAMIAN trial } \\
\text { investigates impact of } 123 \text { I-metomidate on } \\
\text { clinical management }(90)\end{array}$ \\
\hline \multirow[t]{3}{*}{${ }^{177}$ Lu-3BP-277 } & $\begin{array}{l}\text { Neurotensin } \\
\text { receptor } 1\end{array}$ & $\begin{array}{l}\text { Ductal pancreatic } \\
\text { adenocarcinoma }\end{array}$ & Kidney & $\begin{array}{l}\text { Neurotensin receptor } 1 \text { is promising target } \\
\text { with overexpression in breast cancer, } \\
\text { pancreatic adenocarcinoma, prostate } \\
\text { cancer and lung cancer (85) }\end{array}$ \\
\hline & & & & $\begin{array}{l}\text { Feasibility study demonstrated partial } \\
\text { response in patients with pancreatic } \\
\text { adenocarcinoma and extensive tumor } \\
\text { burden }(86)\end{array}$ \\
\hline & & & & $\begin{array}{l}\text { PET-guided strategies for risk stratification are } \\
\text { needed (91) }\end{array}$ \\
\hline
\end{tabular}

be used with care in patients who are not planned to undergo stem cell transplantation as part of therapy, given the significant myelosuppression that can occur. Nonetheless, as there is an increasing body of evidence on relevant hematotoxicity, which may result even in bone marrow ablation, autologous stem cell support is essential before the CXCR4-directed endoradiotherapy $(78,81)$.

\section{I-Metomidate}

With an annual incidence of $0.7-2.0$ cases per 1 million inhabitants, adrenocortical cancer is a rare but extremely aggressive disease (82). Hahner et al. have investigated the radiolabeled iodometomidate theranostics of adrenocortical cancer (Table 2) $(83,84)$. In a feasibility study, 11 patients with nonresectable adrenocortical cancer that demonstrated sufficient uptake on ${ }^{123}$ I-metomidate SPECT underwent a total of 19 treatment cycles (1.6-20 GBq of ${ }^{131}$ I-metomidate per cycle, 1-3 cycles). Transient bone marrow depression was noted in up to $11 \%$ of patients. According to RECIST 1.1, best response was classified as partial response in 1 case, stable disease in 5 patients, and progressive disease in the remaining patients. In the 6 patients demonstrating controlled disease, overall survival was 13 mo (range, 0.35-33 mo) (83). However, metomidate is rapidly inactivated by endogenous esterases, which in turn may hamper diagnostic accuracy and therapeutic efficacy. Thus, Hahner et al. have recently introduced the theranostic pair ${ }^{123} \mathrm{I} /{ }^{131} \mathrm{I}$-azetidinylamide, which has a comparable degree of inhibition of CYP11B enzyme activity but shows higher metabolic stability in vitro than its predecessor, metomidate. Target-to-background ratios increased dramatically, enabling dosimetry-based tumor doses of up to $180 \mathrm{~Gy}$ administered to 3 patients (84).

\section{Lu-3BP-227}

Neurotensin plays a role in lipid ingestion; stimulation of pancreatic, biliary, and gastric acid secretion; and small-bowel motility. Among 3 subtypes, neurotensin receptor 1 is a promising target for cancer treatment, as it is overexpressed in breast cancer $(91 \%)$, ductal pancreatic adenocarcinomas $(75 \%)$, prostate cancer cells, and lung adenocarcinoma (60\%) (85). Baum et al. described 3 patients with ductal pancreatic adenocarcinoma who underwent radionuclide therapy with ${ }^{177} \mathrm{Lu}-3 \mathrm{P}-227$ (range, 5.1-7.5 GBq) (Table 2) (86). In that feasibility study, all patients showed clear uptake in tumor lesions up to $96 \mathrm{~h}$ after injection, with the kidney as the dose-limiting organ. One patient, who received 3 intraperitoneal administrations at 8- to 10-wk intervals, demonstrated favorable results, with imaging-based partial response and significant reduction of pain along with improved quality of life (Fig. 4). This initial report provides evidence of the feasibility of 


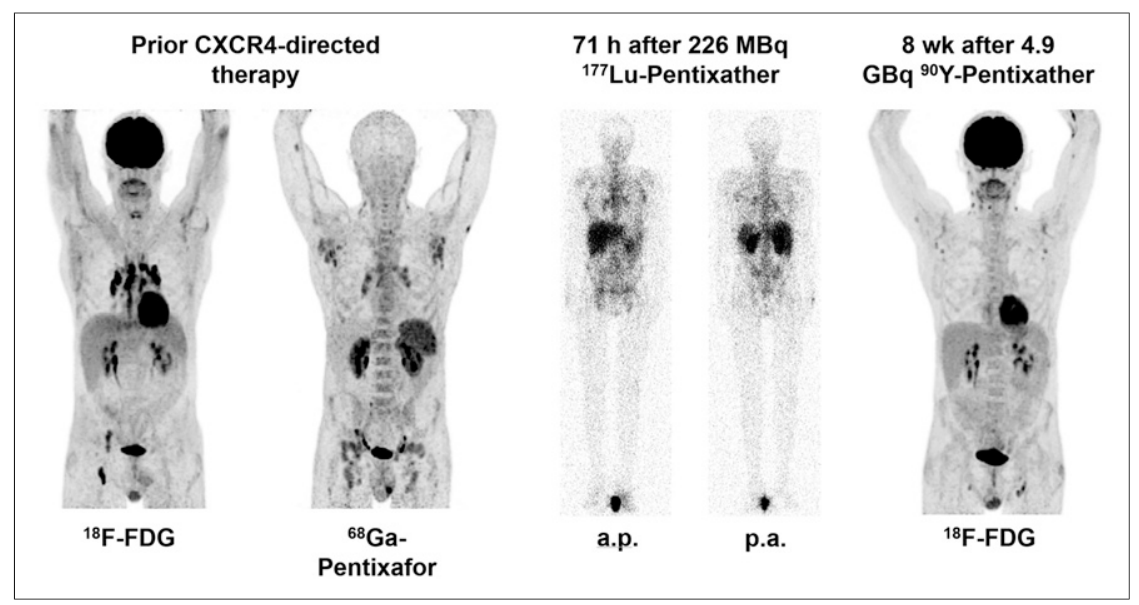

FIGURE 3. A 55-y-old man with history of peripheral T-cell lymphoma who was referred for evaluation of CXCR4-directed endoradiotherapy. Patient had experienced disease relapse in multiple lymph nodes 2 mo after tandem high-dose chemotherapy and subsequent autologous stem cell transplantation. (Left) At initial restaging, both ${ }^{68} \mathrm{Ga}-$ pentixafor PET/CT and ${ }^{18} \mathrm{~F}-\mathrm{FDG}$ PET/CT as standard of reference were performed, with CXRC4-directed PET demonstrating more sites of disease than ${ }^{18} \mathrm{~F}-\mathrm{FDG}$. (Middle) Subsequent pretherapeutic dosimetry with $226 \mathrm{MBq}$ of ${ }^{177} \mathrm{Lu}$-pentixather confirmed persistent radiotracer accumulation and allowed for individualized activity calculation. (Right) With kidney as dose-limiting organ, $4.9 \mathrm{GBq}$ of ${ }^{90} \mathrm{Y}$-pentixather could be administered and was combined with another cycle of high-dose chemotherapy with bendamustine $\left(200 \mathrm{mg} / \mathrm{m}^{2}\right)$ and autologous stem cell transplantation. Eight weeks after therapy, partial response could be recorded. a.p. $=$ anteroposterior; p.a. $=$ posteroanterior.

${ }^{177} \mathrm{Lu}-3 \mathrm{P}-227$ in pancreatic adenocarcinoma, along with a high safety profile (reversible grade 2 anemia) (86).

\section{TRAINING REQUIREMENTS FOR NUCLEAR MEDICINE PRACTITIONERS}

The increased use of theranostics for the diagnosis and treatment of multiple tumor entities has created a need for nuclear medicine practitioners with substantial training in the field of radionuclide therapy. Thus, skills beyond conventional radioisotope imaging are

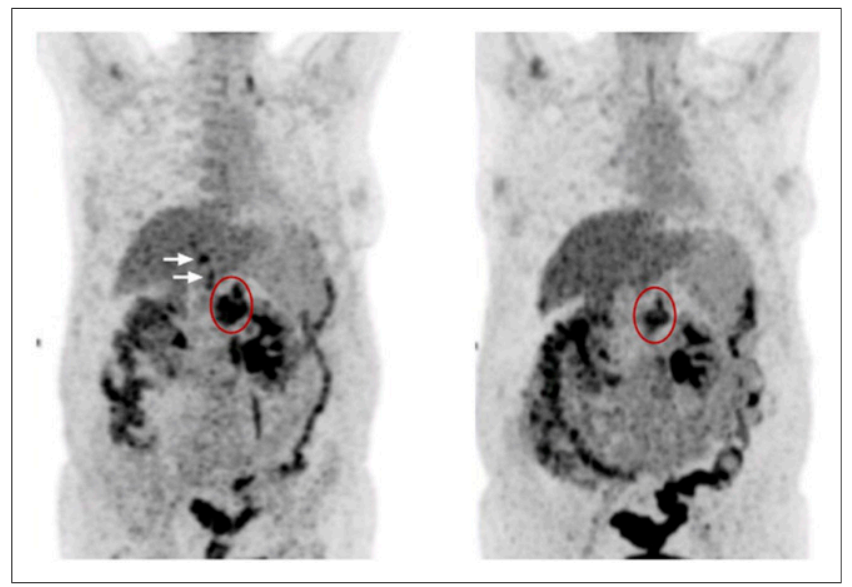

FIGURE 4. ${ }^{18} \mathrm{~F}-\mathrm{FDG}$ PET of 59-y-old woman with ductal pancreatic adenocarcinoma with metastases in liver, lung, lymph nodes, and peritoneum. (Left) Pretherapeutic imaging demonstrated primary tumor (encircled) and liver metastases (arrows). (Right) After 3 cycles of ${ }^{177} \mathrm{Lu}-3 \mathrm{BP}-277$ (cumulative activity of $19.4 \mathrm{GBq}$ ), partial response with reduction in both size and metabolic activity of primary (along with diminished liver lesions) was appreciated. (Modified from (86).) of the utmost importance to face the challenges of performing endoradiotherapies in clinical practice (87). These challenges include, but are not limited to, dedicated administration protocols, understanding of the underlying biologic pathways and complex kinetics of a radiotherapeutic agent, the appropriate use of dosimetry in different clinical scenarios, and addressing acute or delayed therapeutic side effects $(87,88)$. We as a nuclear medicine community cannot lose this momentum presented to us to further enrich the practice of nuclear medicine and to deliver on the theranostic promise for the sake of our (often palliative) patients with cancer.

\section{CONCLUSION}

Performing endoradiotherapy infusion procedures is not a trivial task and requires considerable medical knowledge and astute decision making on the part of the nuclear medicine physician. ${ }^{177} \mathrm{Lu}-\mathrm{PSMA}$ therapy will almost certainly soon be FDA-approved, potentially opening the floodgates of endoradiotherapy in the United States and helping to further widespread acceptance of this technique. Going forward, nuclear medicine training must emphasize acquiring the necessary skills for performing these important procedures. We have likely only begun to scratch the surface of potential applications of theranostic agents, and this active area of research and burgeoning clinical care can drive the field of nuclear medicine to unprecedented levels. As a field, we must do everything possible to leverage this unique opportunity.

\section{DISCLOSURE}

Johns Hopkins Medical Center was a site for the Progenics Azedra trial. Lilja Solnes was the site principal investigator and received salary support. No other potential conflict of interest relevant to this article was reported.

\section{REFERENCES}

1. McCready VR. Radioiodine: the success story of nuclear medicine: 75 th anniversary of the first use of iodine-131 in humans. Eur J Nucl Med Mol Imaging. 2017;44:179-182.

2. Fahey FH, Grant FD, Thrall JH. Saul Hertz, MD, and the birth of radionuclide therapy. EJNMMI Phys. 2017;4:15.

3. Kaminski MS, Tuck M, Estes J, et al. ${ }^{131}$ I-tositumomab therapy as initial treatment for follicular lymphoma. N Engl J Med. 2005;352:441-449.

4. Jacene HA, Filice R, Kasecamp W, Wahl RL. Comparison of ${ }^{90}$ Y-ibritumomab tiuxetan and ${ }^{131}$ I-tositumomab in clinical practice. J Nucl Med. 2007;48:17671776.

5. Vallabhajosula S, Nikolopoulou A, Jhanwar YS, et al. Radioimmunotherapy of metastatic prostate cancer with ${ }^{177} \mathrm{Lu}$-DOTAhuJ591 anti prostate specific membrane antigen specific monoclonal antibody. Curr Radiopharm. 2016;9: 44-53.

6. Kendi AT, Moncayo VM, Nye JA, Galt JR, Halkar R, Schuster DM. Radionuclide therapies in molecular imaging and precision medicine. PET Clin. 2017;12: 93-103.

7. Agrawal A, Rangarajan V, Shah S, Puranik A, Purandare N. MIBG (metaiodobenzylguanidine) theranostics in pediatric and adult malignancies. Br J Radiol. 2018;91:20180103. 
8. Giammarile F, Chiti A, Lassmann M, Brans B, Flux G; EANM. EANM procedure guidelines for ${ }^{131} \mathrm{I}$-meta-iodobenzylguanidine $\left({ }^{131} \mathrm{I}\right.$-mIBG) therapy. Eur J Nucl Med Mol Imaging. 2008;35:1039-1047.

9. Weiss B, Vora A, Huberty J, Hawkins RA, Matthay KK. Secondary myelodysplastic syndrome and leukemia following ${ }^{131}$ I-metaiodobenzylguanidine therapy for relapsed neuroblastoma. J Pediatr Hematol Oncol. 2003;25:543-547.

10. Garaventa A, Gambini C, Villavecchia G, et al. Second malignancies in children with neuroblastoma after combined treatment with ${ }^{131}$ I-metaiodobenzylguanidine. Cancer. 2003;97:1332-1338.

11. Vallabhajosula S, Nikolopoulou A. Radioiodinated metaiodobenzylguanidine (MIBG): radiochemistry, biology, and pharmacology. Semin Nucl Med. 2011;41: 324-333.

12. Gonias S, Goldsby R, Matthay KK, et al. Phase II study of high-dose $\left[{ }^{131} \mathrm{I}\right]$ metaiodobenzylguanidine therapy for patients with metastatic pheochromocytoma and paraganglioma. J Clin Oncol. 2009;27:4162-4168.

13. Pryma DA, Chin BB, Noto RB, et al. Efficacy and safety of high-specific-activity ${ }^{131}$ I-MIBG therapy in patients with advanced pheochromocytoma or paraganglioma. J Nucl Med. 2019;60:623-630.

14. Bomanji JB, Wong W, Gaze MN, et al. Treatment of neuroendocrine tumours in adults with ${ }^{131}$ I-MIBG therapy. Clin Oncol (R Coll Radiol). 2003;15:193-198.

15. Castellani MR, Seregni E, Maccauro M, et al. MIBG for diagnosis and therapy of medullary thyroid carcinoma: is there still a role? $Q \mathrm{~J}$ Nucl Med Mol Imaging. 2008;52:430-440.

16. Matthay KK, Yanik G, Messina J, et al. Phase II study on the effect of disease sites, age, and prior therapy on response to iodine-131-metaiodobenzylguanidine therapy in refractory neuroblastoma. J Clin Oncol. 2007;25:1054-1060.

17. Johnson K, McGlynn B, Saggio J, et al. Safety and efficacy of tandem ${ }^{131} \mathrm{I}-$ metaiodobenzylguanidine infusions in relapsed/refractory neuroblastoma. Pediatr Blood Cancer. 2011;57:1124-1129.

18. Matthay KK, Weiss B, Villablanca JG, et al. Dose escalation study of no-carrieradded ${ }^{131}$ I-metaiodobenzylguanidine for relapsed or refractory neuroblastoma: new approaches to neuroblastoma therapy consortium trial. J Nucl Med. 2012;53:11551163.

19. Ramage JK, Ahmed A, Ardill J, et al. Guidelines for the management of gastroenteropancreatic neuroendocrine (including carcinoid) tumours (NETs). Gut. 2012;61: 6-32.

20. Strosberg J, El-Haddad G, Wolin E, et al. Phase 3 trial of ${ }^{177}$ Lu-dotatate for midgut neuroendocrine tumors. N Engl J Med. 2017;376:125-135.

21. Hicks RJ, Kwekkeboom DJ, Krenning E, et al. ENETS consensus guidelines for the standards of care in neuroendocrine neoplasia: peptide receptor radionuclide therapy with radiolabeled somatostatin analogues. Neuroendocrinology. 2017;105: 295-309.

22. Brabander T, van der Zwan WA, Teunissen JJM, et al. Long-term efficacy, survival, and safety of $\left[{ }^{177} \mathrm{Lu}-\mathrm{DOTA}{ }^{0}, \mathrm{Tyr}^{3}\right]$ octreotate in patients with gastroenteropancreatic and bronchial neuroendocrine tumors. Clin Cancer Res. 2017;23: 4617-4624.

23. Pencharz D, Gnanasegaran G, Navalkissoor S. Theranostics in neuroendocrine tumours: somatostatin receptor imaging and therapy. Br J Radiol. 2018;91:20180108.

24. Pavel M, Baudin E, Couvelard A, et al. ENETS consensus guidelines for the management of patients with liver and other distant metastases from neuroendocrine neoplasms of foregut, midgut, hindgut, and unknown primary. Neuroendocrinology. 2012;95:157-176.

25. Pavel M, Valle JW, Eriksson B, et al. ENETS consensus guidelines for the standards of care in neuroendocrine neoplasms: systemic therapy-biotherapy and novel targeted agents. Neuroendocrinology. 2017;105:266-280.

26. Neuroendocrine and adrenal tumors. National Comprehensive Cancer Network website. https://www.nccn.org/professionals/physician_gls/pdf/neuroendocrine.pdf. Published March 5, 2019. Accessed July 15, 2019.

27. Knigge U, Capdevila J, Bartsch DK, et al. ENETS consensus recommendations for the standards of care in neuroendocrine neoplasms: follow-up and documentation. Neuroendocrinology. 2017;105:310-319.

28. Brabander T, van der Zwan WA, Teunissen JJM, et al. Pitfalls in the response evaluation after peptide receptor radionuclide therapy with $\left[{ }^{177} \mathrm{Lu}-\mathrm{DOTA}{ }^{0}, \mathrm{Tyr}^{3}\right]$ octreotate. Endocr Relat Cancer. 2017;24:243-251.

29. Hope TA, Abbott A, Colucci K, et al. NANETS/SNMMI procedure standard for somatostatin receptor-based peptide receptor radionuclide therapy with ${ }^{177} \mathrm{Lu}$ DOTATATE. J Nucl Med. 2019;60:937-943.

30. Vaughan E, Machta J, Walker M, Toumpanakis C, Caplin M, Navalkissoor S. Retreatment with peptide receptor radionuclide therapy in patients with progressing neuroendocrine tumours: efficacy and prognostic factors for response. $\mathrm{Br} \mathrm{J}$ Radiol. 2018;91:20180041.

31. Kong G, Grozinsky-Glasberg S, Hofman MS, et al. Efficacy of peptide receptor radionuclide therapy for functional metastatic paraganglioma and pheochromocytoma. J Clin Endocrinol Metab. 2017;102:3278-3287.
32. Maier H, Ofner D, Hittmair A, Kitz K, Budka H. Classic, atypical, and anaplastic meningioma: three histopathological subtypes of clinical relevance. J Neurosurg. 1992;77:616-623.

33. Bartolomei M, Bodei L, De Cicco C, et al. Peptide receptor radionuclide therapy with ${ }^{90}$ Y-DOTATOC in recurrent meningioma. Eur J Nucl Med Mol Imaging. 2009;36:1407-1416.

34. Kreissl MC, Hanscheid H, Lohr M, et al. Combination of peptide receptor radionuclide therapy with fractionated external beam radiotherapy for treatment of advanced symptomatic meningioma. Radiat Oncol. 2012;7:99.

35. Kleihues P, Louis DN, Scheithauer BW, et al. The WHO classification of tumors of the nervous system. J Neuropathol Exp Neurol. 2002;61:215-225.

36. Mirimanoff RO, Dosoretz DE, Linggood RM, Ojemann RG, Martuza RL. Meningioma: analysis of recurrence and progression following neurosurgical resection. J Neurosurg. 1985;62:18-24.

37. Kasi PM, Sharma A, Jain MK. Expanding the indication for novel theranostic ${ }^{177} \mathrm{Lu}$-dotatate peptide receptor radionuclide therapy: proof-of-concept of PRRT in Merkel cell cancer. Case Rep Oncol. 2019;12:98-103.

38. Salavati A, Puranik A, Kulkarni HR, Budiawan H, Baum RP. Peptide receptor radionuclide therapy (PRRT) of medullary and nonmedullary thyroid cancer using radiolabeled somatostatin analogues. Semin Nucl Med. 2016;46:215-224.

39. Savelli G, Zaniboni A, Bertagna F, et al. Peptide receptor radionuclide therapy (PRRT) in a patient affected by metastatic breast cancer with neuroendocrine differentiation. Breast Care (Basel). 2012;7:408-410.

40. Henriksen G, Breistol K, Bruland OS, Fodstad O, Larsen RH. Significant antitumor effect from bone-seeking, alpha-particle-emitting ${ }^{223} \mathrm{Ra}$ demonstrated in an experimental skeletal metastases model. Cancer Res. 2002;62:3120-3125.

41. Henriksen G, Fisher DR, Roeske JC, Bruland OS, Larsen RH. Targeting of osseous sites with alpha-emitting ${ }^{223} \mathrm{Ra}$ : comparison with the beta-emitter ${ }^{89} \mathrm{Sr}$ in mice. J Nucl Med. 2003;44:252-259.

42. McDevitt MR, Sgouros G, Finn RD, et al. Radioimmunotherapy with alphaemitting nuclides. Eur J Nucl Med. 1998;25:1341-1351.

43. Roodman GD. Mechanisms of bone metastasis. N Engl J Med. 2004;350:16551664.

44. Nilsson S, Franzen L, Parker C, et al. Bone-targeted radium-223 in symptomatic, hormone-refractory prostate cancer: a randomised, multicentre, placebo-controlled phase II study. Lancet Oncol. 2007;8:587-594.

45. Parker CC, Pascoe S, Chodacki A, et al. A randomized, double-blind, dosefinding, multicenter, phase 2 study of radium chloride ( $\mathrm{Ra} 223$ ) in patients with bone metastases and castration-resistant prostate cancer. Eur Urol. 2013;63:189-197.

46. Nilsson S, Strang P, Aksnes AK, et al. A randomized, dose-response, multicenter phase II study of radium-223 chloride for the palliation of painful bone metastases in patients with castration-resistant prostate cancer. Eur J Cancer. 2012;48:678-686.

47. Parker C, Nilsson S, Heinrich D, et al. Alpha emitter radium-223 and survival in metastatic prostate cancer. N Engl J Med. 2013;369:213-223.

48. Smith MR, Parker CC, Saad F, et al. LBA30ERA 223: A phase III trial of radium-223 (Ra-223) in combination with abiraterone acetate and prednisone/ prednisolone for the treatment of asymptomatic or mildly symptomatic chemotherapy-naive patients (pts) with bone-predominant metastatic castration-resistant prostate cancer (mCRPC) [abstract]. Ann Oncol. 2018;29(suppl 8):LBA30.

49. Jadvar H. Value proposition of PSMA-targeted alpha-particle radioligand therapy in metastatic prostate cancer. Eur J Nucl Med Mol Imaging. 2019;46:8-10.

50. Xofigo (radium Ra 223 dichloride) injection, for intravenous use [prescribing information]. Wayne, NJ: Bayer HeathCare Pharmaceuticals Inc.; 2013.

51. Wenter V, Herlemann A, Fendler WP, et al. Radium-223 for primary bone metastases in patients with hormone-sensitive prostate cancer after radical prostatectomy. Oncotarget. 2017;8:44131-44140.

52. Osvaldo GF, Salvador MS, Zael SR, Nora SM. Radium-223 in metastatic hormone-sensitive high-grade prostate cancer: initial experience. Am J Nucl Med Mol Imaging. 2017;7:236-245.

53. Hofman MS, Violet J, Hicks RJ, et al. $\left[{ }^{177} \mathrm{Lu}\right]-P S M A-617$ radionuclide treatment in patients with metastatic castration-resistant prostate cancer (LuPSMA trial): a single-centre, single-arm, phase 2 study. Lancet Oncol. 2018;19:825-833.

54. Coleman R, Aksnes AK, Naume B, et al. A phase IIa, nonrandomized study of radium-223 dichloride in advanced breast cancer patients with bone-dominant disease. Breast Cancer Res Treat. 2014;145:411-418.

55. McKay RR, Bosse D, Gray KP, et al. Radium-223 dichloride in combination with vascular endothelial growth factor-targeting therapy in advanced renal cell carcinoma with bone metastases. Clin Cancer Res. 2018;24:4081-4088.

56. Ghosh A, Heston WD. Tumor target prostate specific membrane antigen (PSMA) and its regulation in prostate cancer. J Cell Biochem. 2004;91:528-539.

57. Afshar-Oromieh A, Babich JW, Kratochwil C, et al. The rise of PSMA ligands for diagnosis and therapy of prostate cancer. J Nucl Med. 2016;57(suppl 3):79S-89S.

58. Afshar-Oromieh A, Hetzheim H, Kratochwil C, et al. The theranostic PSMA ligand PSMA-617 in the diagnosis of prostate cancer by PET/CT: biodistribution 
in humans, radiation dosimetry, and first evaluation of tumor lesions. J Nucl Med. 2015;56:1697-1705.

59. Kratochwil C, Giesel FL, Stefanova M, et al. PSMA-targeted radionuclide therapy of metastatic castration-resistant prostate cancer with ${ }^{177} \mathrm{Lu}$-Labeled PSMA617. J Nucl Med. 2016;57:1170-1176.

60. Baum RP, Kulkarni HR, Schuchardt C, et al. ${ }^{177}$ Lu-labeled prostate-specific membrane antigen radioligand therapy of metastatic castration-resistant prostate cancer: safety and efficacy. J Nucl Med. 2016;57:1006-1013.

61. Rahbar K, Ahmadzadehfar H, Kratochwil C, et al. German multicenter study investigating ${ }^{177} \mathrm{Lu}$-PSMA-617 radioligand therapy in advanced prostate cancer patients. J Nucl Med. 2017;58:85-90.

62. Fendler WP, Kratochwil C, Ahmadzadehfar H, et al. ${ }^{177}$ Lu-PSMA-617 therapy, dosimetry and follow-up in patients with metastatic castration-resistant prostate cancer [in German]. Nuklearmedizin. 2016;55:123-128.

63. Salas Fragomeni RA, Amir T, Sheikhbahaei S, et al. Imaging of nonprostate cancers using PSMA-targeted radiotracers: rationale, current state of the field, and a call to arms. J Nucl Med. 2018;59:871-877.

64. Kratochwil C, Bruchertseifer F, Giesel FL, et al. ${ }^{225}$ Ac-PSMA-617 for PSMAtargeted alpha-radiation therapy of metastatic castration-resistant prostate cancer. J Nucl Med. 2016;57:1941-1944.

65. Rathke H, Kratochwil C, Hohenberger R, et al. Initial clinical experience performing sialendoscopy for salivary gland protection in patients undergoing ${ }^{225}$ Ac-PSMA-617 RLT. Eur J Nucl Med Mol Imaging. 2019;46:139-147.

66. Woodard LE, Nimmagadda S. CXCR4-based imaging agents. J Nucl Med. 2011;52: 1665-1669.

67. Burger JA, Kipps TJ. CXCR4: a key receptor in the crosstalk between tumor cells and their microenvironment. Blood. 2006;107:1761-1767.

68. Kuhne MR, Mulvey T, Belanger B, et al. BMS-936564/MDX-1338: a fully human anti-CXCR4 antibody induces apoptosis in vitro and shows antitumor activity in vivo in hematologic malignancies. Clin Cancer Res. 2013;19:357-366.

69. Murphy PM. Chemokines and the molecular basis of cancer metastasis. $N$ Engl J Med. 2001;345:833-835.

70. Dar A, Schajnovitz A, Lapid K, et al. Rapid mobilization of hematopoietic progenitors by AMD3100 and catecholamines is mediated by CXCR4-dependent SDF-1 release from bone marrow stromal cells. Leukemia. 2011;25:1286-1296.

71. Cashen A, Lopez S, Gao F, et al. A phase II study of plerixafor (AMD3100) plus G-CSF for autologous hematopoietic progenitor cell mobilization in patients with Hodgkin lymphoma. Biol Blood Marrow Transplant. 2008;14: 1253-1261.

72. Pernas S, Martin M, Kaufman PA, et al. Balixafortide plus eribulin in HER2negative metastatic breast cancer: a phase 1, single-arm, dose-escalation trial. Lancet Oncol. 2018;19:812-824.

73. Buck AK, Stolzenburg A, Hanscheid H, et al. Chemokine receptor-directed imaging and therapy. Methods. 2017;130:63-71.

74. Walenkamp AME, Lapa C, Herrmann K, Wester HJ. CXCR4 ligands: the next big hit? J Nucl Med. 2017;58(suppl 2):77S-82S.
75. Herrmann K, Schottelius M, Lapa C, et al. First-in-human experience of CXCR4-directed endoradiotherapy with ${ }^{177} \mathrm{Lu}$ - and ${ }^{90}$ Y-labeled pentixather in advanced-stage multiple myeloma with extensive intra- and extramedullary disease. J Nucl Med. 2016;57:248-251.

76. Lapa C, Herrmann K, Schirbel A, et al. CXCR4-directed endoradiotherapy induces high response rates in extramedullary relapsed multiple myeloma. Theranostics. 2017;7:1589-1597.

77. Lapa C, Hänscheid H, Kircher M, et al. Feasibility of CXCR4-directed radioligand therapy in advanced diffuse large B-cell lymphoma. J Nucl Med. 2019;60:60-64.

78. Werner RA, Weich A, Higuchi T, et al. Imaging of chemokine receptor 4 expression in neuroendocrine tumors: a triple tracer comparative approach. Theranostics. 2017;7:1489-1498.

79. Bluemel C, Hahner S, Heinze B, et al. Investigating the chemokine receptor 4 as potential theranostic target in adrenocortical cancer patients. Clin Nucl Med. 2017;42:e29-e34.

80. Lapa C, Luckerath $\mathrm{K}$, Rudelius M, et al. $\left[{ }^{68} \mathrm{Ga}\right]$ pentixafor-PET/CT for imaging of chemokine receptor 4 expression in small cell lung cancer: initial experience. Oncotarget. 2016;7:9288-9295.

81. Kircher M, Herhaus P, Schottelius M, et al. CXCR4-directed theranostics in oncology and inflammation. Ann Nucl Med. 2018;32:503-511.

82. Fassnacht M, Kroiss M, Allolio B. Update in adrenocortical carcinoma. J Clin Endocrinol Metab. 2013;98:4551-4564.

83. Hahner S, Kreissl MC, Fassnacht M, et al. [ $\left.{ }^{131} \mathrm{I}\right]$ iodometomidate for targeted radionuclide therapy of advanced adrenocortical carcinoma. J Clin Endocrinol Metab. 2012;97:914-922.

84. Hahner S, Heinze B, Herrmann K, et al. $\left[{ }^{123 / 131} \mathrm{I}\right]$ azetidinylamide: a novel radiotracer for diagnosis and treatment of adrenocortical tumours-from bench to bedside. Endocrine Abstracts. 2015;37:OC1.3.

85. Morgat C, Mishra AK, Varshney R, Allard M, Fernandez P, Hindie E. Targeting neuropeptide receptors for cancer imaging and therapy: perspectives with bombesin, neurotensin, and neuropeptide-Y receptors. J Nucl Med. 2014;55:1650-1657.

86. Baum RP, Singh A, Schuchardt C, et al. ${ }^{177} \mathrm{Lu}-3 \mathrm{BP}-227$ for neurotensin receptor 1-targeted therapy of metastatic pancreatic adenocarcinoma: first clinical results. J Nucl Med. 2018;59:809-814.

87. Mankoff D, Pryma DA. Nuclear medicine training: what now? J Nucl Med. 2017;58:1536-1538.

88. Eberlein U, Cremonesi M, Lassmann M. Individualized dosimetry for theranostics: necessary, nice to have, or counterproductive? J Nucl Med. 2017;58(suppl 2): 97S-103S

89. Kraeber-Bodéré F, Rousseau C, Bodet-Milin C, et al. Tumor immunotargeting using innovative radionuclides. Int J Mol Sci. 2015;16:3932-3954.

90. Combined FDG-PET and ${ }^{123}$ I-Iodometomidate Imaging for Adrenal Neoplasia (FAMIAN). ClinicalTrial.gov website. https://clinicaltrials.gov/ct2/show/NCT02010957. Published December 13, 2013. Updated April 11, 2018. Accessed January 16, 2020.

91. Fendler WP, Baum RP. NTR is the new SSTR? Perspective for neurotensin receptor 1 (NTR)-directed theranostics. J Nucl Med. 2017;58:934-935. 